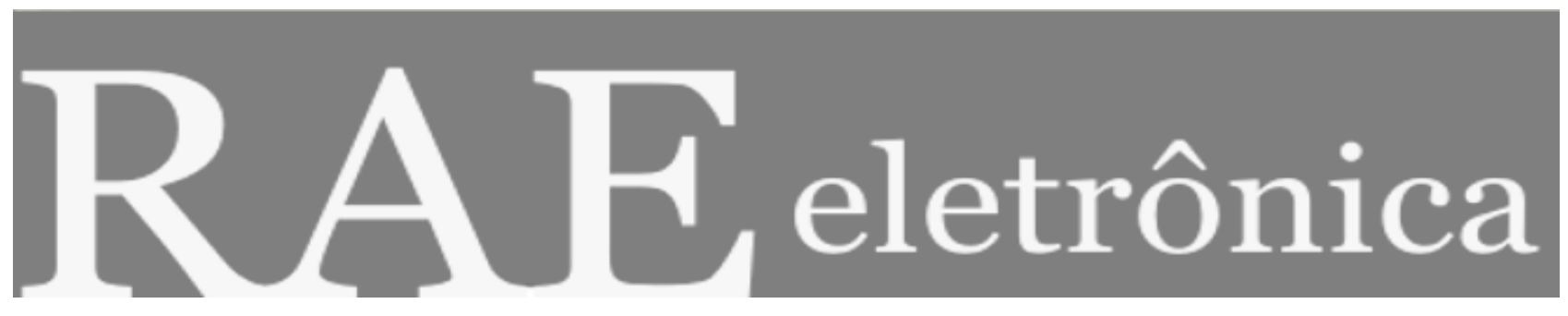

ISSN 1676-5648

www.fgv.br/raeeletronica

\title{
RELAÇÃO DINÂMICA ENTRE CONFIANÇA, COMPETITIVIDADE E O PROCESSO DE TOMADA DE DECISÃO ÉTICA EM NEGOCIAÇÃO
}

THE DYNAMIC RELATIONSHIP BETWEEN TRUST, COMPETITIVENESS AND THE

\section{ETHICAL DECISION MAKING PROCESS IN NEGOTIATION}

RELACIÓN DINÁMICA ENTRE CONFIANZA, COMPETITIVIDAD Y EL PROCESO DE TOMA

\section{DE DECISIÓN ÉTICA EN NEGOCIACIÓN}

\section{Filipe João Bera de Azevedo Sobral}

Professor da Escola Brasileira de Administração Pública e de Empresas da Fundação Getulio Vargas Rio de Janeiro - RJ, Brasil

filipe.sobral@fgv.br

Recebido em 21.05.2010. Aprovado em 07.12.2010. Disponibilizado em 10.12.2010

Avaliado pelo sistema double blind review

Editor científico: Mário Sacomano Neto 


\title{
RESUMO
}

Os dilemas éticos são componentes inevitáveis da negociação, um processo de troca social central a todas as interações humanas. Por essa razão, é importante compreender o que motiva os gestores a agir de uma forma eticamente questionável em negociações empresariais. Usando uma amostra de 298 participantes em cursos de educação executiva, este estudo busca analisar em que medida diferenças individuais ao nível da personalidade condicionam o julgamento moral de práticas negociais eticamente ambíguas e as intenções comportamentais em seis cenários representativos de situações negociais que envolvem dilemas éticos. Os resultados sugerem que os dois traços de personalidade estudados - confiança interpessoal e competitividade - exercem uma influência significativa não apenas na forma como os gestores avaliam a moralidade de práticas negociais eticamente ambíguas, mas também na sua intenção comportamental em cenários negociais específicos. Os resultados podem contribuir para melhorar a compreensão do processo de tomada de decisão ética em negociação.

PALAVRAS-CHAVE Negociação, ética, tomada de decisão, confiança, competitividade.

\begin{abstract}
Ethical dilemmas are inescapable components of a negotiation, a social exchange process central to all human interactions. It is thus important to understand what motivates managers to engage in ethically questionable behaviors in business negotiations. Using a sample of 298 students enrolled in executive training programs, this study tries to analyze to what extent individuals differences in personality influence the moral judgment of ethically ambiguous negotiation practices and behavioral intentions in six scenarios representing negotiation situations with ethical dilemmas. Results suggest that both personality traits studied - interpersonal trust and competitiveness - have a significant influence not only on how managers judge the morality of ethically ambiguous negotiation tactics, but also on their behavioral predisposition in specific negotiation scenarios. These findings may significantly contribute to the theoretical understanding of ethical decision making processes in negotiation.
\end{abstract}

KEYWORDS Negotiation, ethics, decision making, trust, competitiveness.

RESUMEN Los dilemas éticos son componentes inevitables de la negociación, un proceso de intercambio social central en todas las interacciones humanas. Por esa razón, es importante comprender lo que motiva a los gestores a actuar de forma éticamente cuestionable en las negociaciones empresariales. Usando una muestra de 298 participantes de cursos de educación ejecutiva, este estudio se propone analizar en qué medida las diferencias individuales al nivel de personalidad condicionan el juicio moral de prácticas negociales éticamente ambiguas y las intenciones comportamentales en seis escenarios representativos de situaciones negociales que incluyen dilemas éticos. Los resultados sugieren que los dos rasgos de personalidad estudiados -confianza interpersonal y competitividad- ejercen una influencia significativa no sólo en la forma como los gestores evalúan la moralidad de las prácticas negociales éticamente ambiguas, sino también en su intención comportamental en escenarios negociales específicos. Los resultados pueden contribuir para mejorar la comprensión del proceso de toma de decisión ética en negociación.

PALABRAS CLAVE Negociación, ética, toma de decisión, confianza, competitividad. 


\section{INTRODUÇÃO}

Os dilemas éticos que os administradores enfrentam no processo de tomada de decisão em contextos empresariais são vistos como objeto de estudo provocativo e desafiador (TREVINO, WEAVER e REYNOLDS, 2006), especialmente numa área como a Administração, historicamente acusada de comportamentos pouco éticos, guiados exclusivamente pela racionalidade instrumental (SOLOMON, 1991). Esses desvios éticos incorridos pelos executivos não só têm um custo elevado para as organizações, como têm implicações na legitimidade das nossas instituições sociais e no bem-estar da sociedade. Além disso, o estudo empírico dos processos pelos quais os indivíduos fazem escolhas morais pode eventualmente levar ao desenvolvimento de um ambiente empresarial mais ético (GOOLSBY e HUNT, 1992).

Uma das práticas empresariais mais interessantes para se estudar a honestidade e a ética na tomada de decisões é a negociação. Sendo, por definição, uma interação socialmente motivada entre indivíduos ou grupos com interesses divergentes, a negociação é uma atividade intrinsecamente rica em dilemas éticos (BARRY e ROBINSON, 2002; MENKEL-MEADOW e WHELER, 2004). Ao procurar conciliar esses interesses concorrentes sem sacrificar os interesses individuais, as partes podem sentirse tentadas a adotar um comportamento defensivo, furtivo e, em alguns casos, manipulador e desonesto. De fato, apesar de esses comportamentos serem minimizados na presença de mecanismos sociais, como confiança e reciprocidade (GRANOVETTER, 1985, UZZI, 1997), a negociação tem o potencial de promover comportamentos oportunistas na tentativa de maximizar os interesses próprios, uma vez que as partes possuem assimetrias de informação (KOLLOCK, 1994; LAX e SEBENIUS, 1998).

Por outro lado, além de os desvios éticos serem comuns em negociação (RIVERS e LYTLE, 2007; VOLKEMA, FLECK e HOFMEISTER-TOTH, 2004; MURNIGHAN e outros, 1999), alguns pesquisadores sugerem que certas formas de desonestidade podem ser apropriadas e mesmo necessárias para que se possa ser eficaz em negociação (CARSON, 1993; DEES e CRAMPTON, 1991; LEWICKI e ROBINSON, 1998). No entanto, apesar do reconhecimento da relevância da negociação como área rica em dilemas éticos, poucos têm sido os estudos que procuram compreender como algumas características da personalidade do negociador influenciam o processo de tomada de decisão em práticas negociais eticamente ambíguas (LEWICKI, SAUNDERS, BARRY, 2009). 
O objetivo deste estudo consiste em procurar entender como dois traços de personalidade confiança interpessoal e competitividade - influenciam o julgamento moral e a intenção comportamental das pessoas em negociação. Mais especificamente, esta pesquisa busca analisar em que medida as diferenças individuais ao nível da personalidade de um negociador condicionam o seu julgamento moral de práticas negociais eticamente ambíguas e as suas intenções comportamentais em seis cenários que expressam situações que envolvem dilemas éticos. Usando diversos modelos de equações estruturais, as relações dinâmicas entre confiança interpessoal, competitividade, julgamento moral e intenção comportamental são avaliadas.

\section{MARCO CONCEITUAL E HIPÓTESES}

O presente estudo baseia-se em contribuições da psicologia social, da filosofia moral, da ética empresarial e do comportamento organizacional, e tem três pressupostos básicos. Primeiro, que o processo de tomada de decisão ética tem início quando uma pessoa reconhece que um determinado assunto constitui um dilema de natureza ética (HUNT e VITELL, 1986; JONES, 1991; REST, 1986). Segundo, que o julgamento que uma pessoa faz sobre esse assunto irá influenciar a sua intenção comportamental e, consequentemente, o seu comportamento (AJZEN e FISHBEIN , 1980; FISHBEIN e AJZEN, 1975). Terceiro, que fatores de natureza individual e contextual irão influenciar o julgamento moral e as intenções comportamentais das pessoas expostas a esses dilemas éticos (CALLANAN e outros, 2010; JONES, 1991; RIVERS e LYTLE, 2007; TREVINO, 1996).

Apesar de existirem diversos modelos teóricos sobre o processo de tomada de decisão ética em contextos organizacionais (BEU, BUCKLEY, HARVEY, 2003; FRITZSCHE, 1991; HUNT e VITELL, 1986; JONES, 1991; REST, 1986; TREVINO, 1986), o suporte empírico para esses modelos é limitado. Especificamente em negociação essas pesquisas são escassas, e ainda não existe um entendimento sobre o que condiciona o julgamento moral dos negociadores e quais as circunstâncias que os levam à adoção de comportamentos mais ou menos éticos. Alguns autores têm proposto algumas relações, que no entanto ainda carecem de confirmação empírica (LEWICKI, SAUNDERS, BARRY, 2009). O presente estudo tem como objetivo contribuir para que se compreenda melhor como as diferenças individuais na personalidade dos indivíduos condicionam o seu julgamento moral de 
práticas negociais eticamente ambíguas e as suas intenções comportamentais em diferentes situações de negociação que caracterizam dilemas éticos.

A personalidade é tida com um dos principais condicionantes do processo de tomada de decisão ética (BROWN e outros, 2010). Da mesma forma, pesquisas no campo da negociação partem do pressuposto de que a personalidade é relevante para a compreensão do processo decisório em negociação e dos seus resultados (BARRY e FRIEDMAN, 1998). No entanto, enquanto a sugestão da influência da personalidade é intuitivamente apelativa, a maioria dos estudos tem gerado resultados inconsistentes no que respeita ao suporte dessas relações (WALL e BLUM, 1991). King e Hinson (1994) argumentam que essas inconsistências podem ser parcialmente atribuídas à utilização de dimensões da personalidade que não estão conceitualmente relacionadas à negociação, como o maquiavelismo (BASS, BARNETT, BROWN, 1999), e o lócus de controle (SHAPEERO e outros, 2003). Estudos recentes revelam que outras características de personalidade podem ajudar a compreender melhor o processo de tomada de decisão em negociação, nomeadamente a forma como os indivíduos avaliam a moralidade e se comportam em situações negociais. Esses traços de personalidade são: o estilo negocial e a confiança interpessoal (ELAHEE e BROOKS, 2004; MINTU-WIMSATT, 2002). Nesse sentido, tendo por base o modelo de tomada de decisão ética de Rest (1986), apresenta-se um modelo de pesquisa parcialmente explicativo do processo de tomada de decisão ética em negociação que destaca os referidos traços de personalidade (Figura 1).

Figura 1 - Modelo de pesquisa

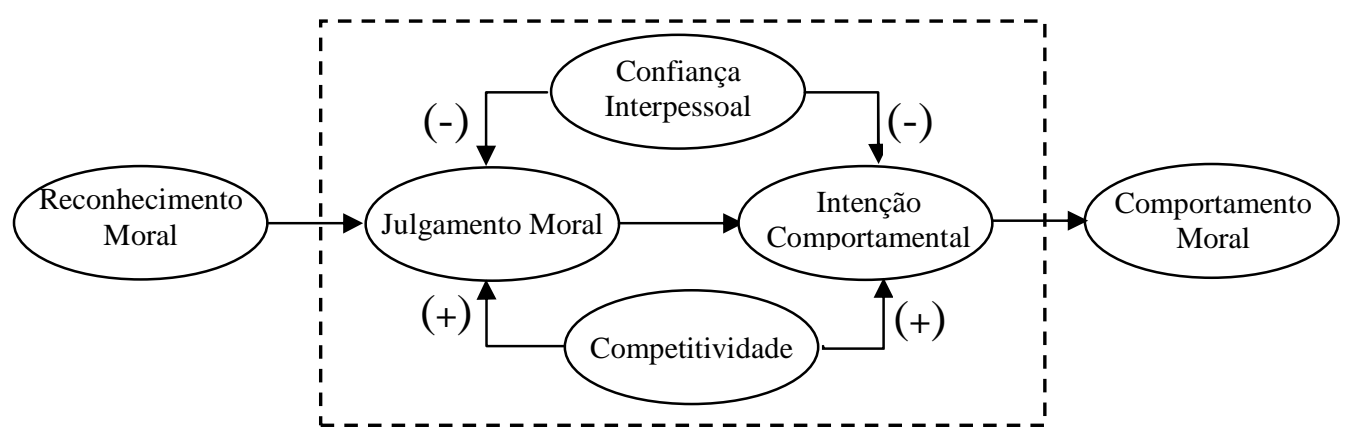


Em seguida, são ainda apresentados os principais conceitos teóricos e a argumentação teórica que permite sustentar as hipóteses de pesquisa que relacionam cada um desses construtos e que permitem operacionalizar a pesquisa.

\section{Julgamento moral e intenção comportamental}

O julgamento moral é uma avaliação individual sobre a aceitabilidade ética de um determinado comportamento (GIFFORD e NORRIS, 1987; SPARKS e PAN, 2010). Por sua vez, a intenção comportamental é uma predisposição para adotar um determinado comportamento numa situação específica. A relação entre o julgamento moral e a intenção comportamental é sustentada pelas teorias da ação racional (FISHBEIN e AJZEN, 1975) e do comportamento planejado (AJZEN, 1985; 1991).

A teoria da ação racional sustenta que uma parte significativa do comportamento humano tem um fundamento racional que o torna previsível por meio da análise da intenção de agir. Essa intenção de agir é fortemente influenciada pela atitude perante o comportamento em questão e pela norma subjetiva - ou pressão social - associada a esse comportamento (FISHBEIN e AJZEN, 1975). Assim, muitos comportamentos são antecipados por uma intenção de agir que resulta de uma avaliação racional da realidade (FISHBEIN e AJZEN, 1975). A TRA não é isenta de críticas, tendo sido alvo de inúmeras contestações de autores que apontavam a limitada possibilidade de generalização da teoria, argumentando que esta pressupõe o absoluto controle do indivíduo sobre a sua capacidade de agir, ignorando igualmente o dilema da existência de comportamentos alternativos (EAGLY e CHAIKEN, 1993; SHEPPARD, HARTWICK, WARSHAW, 1988). No entanto, apesar das críticas, diversos estudos confirmam que a intenção de agir ainda permanece como um indicador fiável do comportamento (HILL e outros, 1987; AJZEN e FISHBEIN, 1980).

A teoria do comportamento planejado sustenta que o comportamento e a intenção de agir resultam da influência combinada da atitude individual perante esse comportamento, da norma subjetiva e da percepção sobre o controle do comportamento em causa. Ou seja, a percepção do indivíduo sobre a sua capacidade de realizar determinada ação condiciona, dessa forma, a sua intenção (AJZEN, 1985; AJZEN, 1991). Assim, é de se esperar que o julgamento moral de dilemas éticos da negociação esteja fortemente relacionado à sua intenção comportamental.

Revisões de diversos estudos concluem que existe um suporte empírico consistente que corrobora a relação entre o julgamento moral e a intenção comportamental (KIM e HUNTER, 1993; O'FALLON e BUTTERFIELD, 2005). Dessa forma, tendo por base as contribuições teóricas 
apresentadas, sustenta-se a hipótese de que a intenção comportamental perante práticas negociais eticamente questionáveis é fortemente influenciada pelo julgamento e avaliação que um indivíduo faz dessas práticas.

\footnotetext{
$\mathbf{H}_{1}$ : O julgamento moral de práticas eticamente ambíguas exerce uma influência significativa na intenção comportamental dos negociadores.
}

\section{Competitividade}

O estilo negocial ou de resolução de conflitos pode ser definido como um traço de personalidade, relativamente estável, responsável por padrões de comportamento e reações em situações de conflito (SHELL, 2001). Tem como pressuposto básico que os indivíduos diferem quanto às suas orientações preferenciais ao lidar com situações de conflito (GILKEY e GREENHALGH 1986). Vários autores sugerem que essa orientação depende essencialmente do grau de preocupação que um negociador tem relativamente aos seus próprios interesses e relativamente aos interesses dos outros - modelo de interesses duais ou dual concerns model (THOMAS, 1976; PRUITT, 1983). Apesar da proliferação de modelos conceituais de estilos de resolução de conflitos, todos reconhecem a existência de dois estilos negociais conceitualmente opostos: o estilo cooperativo e o estilo competitivo (FEIDAKIS e TSAOUSSIS, 2009).

Os negociadores cooperativos são aqueles que têm como objetivo uma solução razoável que, solucionando o conflito de interesses, maximize os resultados conjuntos, ou seja, têm uma preocupação com os interesses da outra parte. Comportam-se de uma forma afável e sincera, confiando em parâmetros objetivos para guiar as discussões. Maximizam a partilha de informação relevante numa atitude de abertura e de confiança para com a outra parte. Raramente utilizam ameaças e estão dispostos a fazer concessões unilaterais. Como o seu principal objetivo é a resolução do conflito ou problemas entre as partes, procuram diligentemente explorar alternativas e propor novas soluções, que permitam criar valor para ambas as partes (CRAVER, 2003; FISHER e outros, 1991).

Por outro lado, os negociadores competitivos vêem a outra parte como um adversário, sendo que o seu objetivo é a maximização dos próprios resultados. Sentem-se confortáveis em ambientes competitivos, e buscam fazer uso do poder para impor soluções que lhes sejam vantajosas (FEIDAKIS e TSAOUSSIS, 2009). Para isso, recorrem frequentemente a ameaças e começam o processo negocial com ofertas irrealistas. Normalmente, não são abertos e são desconfiados, procurando minimizar a 
partilha de informação com a outra parte. O seu objetivo é satisfazer os seus interesses fazendo o mínimo possível de concessões. Podem ser manipuladores e ignorar alternativas que possam beneficiar a outra parte se essas alternativas não os beneficiarem (CRAVER, 2003; DAWSON, 2001).

No entanto, poucos estudos têm explorado os estilos negociais e a ética no processo de tomada de decisão em contextos organizacionais. Entre estes, destacam-se primeiro uma pesquisa conduzida por Sankaran e Bui (2003), que conclui que os indivíduos competitivos tendem a apresentar menores padrões éticos do que os cooperativos, e depois um estudo de Lewicki e Robinson (1998), que revela que os indivíduos que se classificam como competitivos julgam a moralidade de diversas táticas negociais eticamente ambíguas com maior tolerância do que os que se classificam como cooperativos. Apesar das evidências empíricas sugerirem uma relação entre o estilo negocial e a tomada de decisão ética em negociação, os resultados ainda não são conclusivos.

Considerando as contribuições apresentadas, sustenta-se a hipótese de que quanto mais competitivo o negociador for, maior será a sua aceitabilidade de práticas negociais eticamente ambíguas, uma vez que acredita que estas o auxiliarão a maximizar os seus resultados individuais. Na medida em que um negociador tem como principal preocupação a satisfação dos seus interesses, na qual a outra parte é vista como um adversário, é de esperar que revele um julgamento moral mais permissivo de táticas que envolvam ambiguidade ética e que possam ajudá-lo a alcançar os seus objetivos. O mesmo raciocínio pode ser aplicado à relação entre a competitividade e a intenção comportamental. Assim, sustenta-se que quanto mais competitivo for o negociador, maior será a tendência de agir de forma oportunista, pelo que maior será a intenção de adotar comportamentos eticamente questionáveis.

$\mathbf{H}_{2 \mathrm{a}}$ : A competitividade estará positivamente associada a uma maior aceitabilidade de práticas negociais eticamente ambíguas.

$\mathbf{H}_{2 b}$ : A competitividade estará positivamente associada a uma maior intenção de adotar comportamentos eticamente questionáveis.

\section{Confiança interpessoal}

A confiança interpessoal pode ser definida como "a disposição para aceitar vulnerabilidade baseada em expectativas positivas das intenções ou do comportamento de outro" (ROUSSEAU e outros, 1998: 
395), sendo, portanto, uma variável com efeitos importantes nas relações sociais, entre as quais se inclui a negociação (LEWICKI, TOMLINSON e GILLESPIE, 2006). Se as experiências de confiança nos outros foram recompensados por uma confiança recíproca e por um relacionamento produtivo, a confiança interpessoal deve ser alta. Contrariamente, se foram punidos pelos outros com atitudes de exploração, engano e desonestidade, a sua confiança nos outros deve ser baixa (DE CREMER, VAN DIJK e PILLUTLA, 2010). Indivíduos com uma elevada confiança interpessoal tendem a impor-se elevados padrões morais, raramente recorrendo a mentiras ou enganos, pois acreditam que os outros vão se comportar de uma forma idêntica. Ao contrário, indivíduos desconfiados acreditam que os outros não vão cumprir as regras morais da interação social e por isso mesmo sentem menos pressão para se comportarem honestamente. Como consequência, acreditam na mentira, na manipulação, na distorção de fatos ou em outros comportamentos similares como reações defensivas necessárias (ROTTER, 1980).

No contexto da negociação, essa variável está relacionada com a as expectativas que as partes têm na honestidade dos outros com quem interagem (OLEKALNS e SMITH, 2009; FELLS, 1983) e tem múltiplos efeitos sobre as situações negociais (ROSS e LACROIX, 1996). Especificamente, os negociadores com elevada confiança interpessoal tendem a ser mais cooperativos, pois o seu processo cognitivo é influenciado por uma abordagem mais aberta e colaborativa à negociação (BUTLER, 1999; MINTU-WIMSATT, 2002). Esses negociadores acreditam que os outros não irão usar a informação que partilham durante o processo negocial para se aproveitarem da situação oportunistamente (BUTLER, 1995). Kimmel e outros (1980) também concluíram que a confiança estava associada a uma maior troca de informações entre as partes e a uma menor utilização de táticas de pressão. Por outro lado, negociadores inerentemente desconfiados tendem a comportar-se de uma forma mais competitiva durante a negociação, a compartilhar menos informações com a outra parte e a utilizar com mais frequência táticas de pressão para conseguir concessões (BUTLER, 1995; KIMMEL e outros, 1980). No entanto, a relação entre confiança e o comportamento em negociação é de duplo sentido. Se, por um lado, a confiança condiciona o comportamento dos negociadores, este também influencia a sua confiança. Por exemplo, um estudo recente concluiu que aqueles que são alvo de engano e desonestidade em negociação veem sua confiança interpessoal diminuir (DE CREMER, VAN DIJK e PILLUTLA, 2010).

Vários pesquisadores têm argumentado que confiança e ética são dois conceitos intrinsecamente correlacionados, defendendo que a confiança é um dos principais promotores de um comportamento 
ético (BRIEN, 1998; HOSMER, 1995). De fato, esse construto é particularmente importante no processo de tomada de decisão ética em negociação devido ao elevado grau de risco e vulnerabilidade envolvidos em quase todas as situações de barganha. Corroborando essa ideia, pesquisadores concluíram que a confiança interpessoal está inversamente correlacionada à aceitabilidade dessas táticas negociais eticamente ambíguas, sendo que a correlação é mais forte no caso do julgamento de comportamentos que envolvem o engano ativo da outra parte (ELAHEE e BROOKS, 2004). Dessa forma, sustenta-se a hipótese de que a confiança interpessoal esteja negativamente relacionada ao julgamento moral dos negociadores. Quanto maior for a confiança interpessoal, maior a crença de que a outra parte será honesta, o que favorecerá uma menor tolerância com práticas eticamente questionáveis. Pelo contrário, uma baixa confiança interpessoal significa que a pessoa acredita que a outra parte recorrerá a mentiras ou ao engano, favorecendo a aceitabilidade de algumas táticas negociais eticamente ambíguas.

O mesmo raciocínio pode ser aplicado à relação entre a confiança interpessoal e a intenção comportamental. Assim, sustenta-se que, quanto maior a confiança interpessoal, menor será a tendência de agir de forma oportunista, pelo que menor será a intenção de adotar comportamentos eticamente questionáveis (OLEKALNS e SMITH, 2009). Pelo contrário, uma baixa confiança interpessoal significa que as pessoas acreditam que os outros não vão cumprir as regras morais da interação social e por isso mesmo sentem menos pressão para se comportar honestamente, ou seja, maior será a intenção de utilizar táticas eticamente ambíguas. Dessa forma, apesar do reconhecimento de que a influência da confiança interpessoal na intenção comportamental se dá principalmente via julgamento moral, sustenta-se que a confiança interpessoal também está diretamente relacionada à intenção comportamental.

$\mathbf{H}_{3 \mathbf{a}}$ : A confiança interpessoal estará negativamente associada a uma maior aceitabilidade de práticas negociais eticamente ambíguas.

$\mathbf{H}_{3 \mathbf{b}}$ : A confiança interpessoal estará negativamente associada a uma maior intenção de adotar comportamentos eticamente questionáveis.

\section{METODOLOGIA}




\section{Procedimentos de coleta de dados}

Para testar empiricamente a validade do modelo de pesquisa e das hipóteses subjacentes, foi realizada uma pesquisa de campo com alunos de programas de educação executiva em instituições de ensino superior de referência no Brasil por meio de um questionário estruturado. Os questionários reforçavam a ideia de que não existiam respostas certas ou erradas, de forma a encorajar o respondente a dar uma resposta o menos enviesada possível. Além disso, garantia-se a todos os participantes que as respostas seriam anônimas e tratadas de forma agregada, não existindo nenhum campo de resposta que pudesse identificar o respondente.

No total, foram administrados 298 questionários. Os participantes que constituem a amostra são na sua maioria homens (61\%), têm uma idade média de 36 anos e experiência profissional média de 13 anos. Desses 298 respondentes, 195 (64\%) exercem uma função gerencial, sendo que 12\% deles declaram ocupar um cargo de direção, $30 \%$ se definem como gerentes de nível médio e 58\% como supervisores ou coordenadores de nível operacional.

\section{Instrumentos de medida}

A operacionalização do construto 'julgamento moral' incluiu apenas uma tática representativa de cada categoria por uma questão de parcimônia do instrumento de coleta, apesar de reconhecer que as cinco categorias de práticas negociais eticamente ambíguas analisadas são conceitualmente distintas e que poderiam existir diferenças no processo de tomada de decisão ética em negociação se fossem analisadas separadamente. O julgamento moral foi medido utilizando-se cinco comportamentos representativos de práticas negociais eticamente ambíguas adaptadas a partir da escala Self-Reported Inappropriate Strategies (SINS). Essa escala foi desenvolvida por Robinson e outros (2000) e propõe uma taxonomia de cinco categorias de práticas negociais eticamente ambíguas: (1) táticas competitivas; (2) a distorção da informação; (3) o blefe; (4) a manipulação da rede de contatos da outra parte; e (5) a obtenção fraudulenta de informação. Aos respondentes era pedido que avaliassem a aceitabilidade de comportamentos representativos de cada uma dessas categorias, utilizando uma escala Likert de 7 pontos que variava de "totalmente inaceitável" até "totalmente aceitável". Diversos estudos têm explorado a natureza e a estrutura conceitual da taxonomia proposta, validando-a e considerando-a um instrumento fidedigno (LEWICKI e outros, 2003). O $\alpha$ de Cronbach dessa escala no presente estudo foi de 0,76 . 
Para medir a intenção comportamental dos respondentes foram desenvolvidos seis pequenos cenários que ilustram as principais condições negociais apontadas pela literatura como condicionantes dos julgamentos, intenções e comportamentos morais em uma negociação (LEWICKI e outros, 2009; VOLKEMA e FLEURY, 2002). Dessa forma, os respondentes deveriam avaliar em que medida consideravam provável a utilização de cada um dos cinco comportamentos eticamente ambíguos anteriormente referidos nas situações negociais descritas, utilizando para o efeito uma escala Likert de 7 pontos que variava de "totalmente improvável” até "totalmente provável”. Os $\alpha$ de Cronbach para os seis cenários variaram de 0,73 a 0,84 .

A confiança interpessoal foi medida por meio de uma escala com 4 itens adaptados da escala desenvolvida por Rotter (1967) para avaliar a predisposição individual para confiar no outro. Por sua vez, para medir o estilo negocial, ou seja, a predisposição do negociador para uma abordagem mais competitiva ou mais cooperativa da negociação, foram adaptados 4 itens da escala de competitividade de Ryckman e outros (1996). Em ambas as escalas, pedia-se aos respondentes que indicassem o grau de concordância com cada uma das afirmações, usando para tal uma escala Likert de 7 pontos que variava de "discordo totalmente" até "concordo totalmente". Os $\alpha$ de Cronbach para a escala de competitividade foi de 0,87 e para a escala de confiança interpessoal foi de 0,82 .

\section{Cenários de negociação}

A utilização de cenários tem sido um método utilizado pelos pesquisadores para obter dados empíricos precisos e válidos sobre os julgamentos e comportamentos éticos dos respondentes, uma vez que permitem padronizar uma série de variáveis e torna o processo de tomada de decisão mais real (ALEXANDER e BECKER, 1978; WEBER, 1992). Por essa razão, esse método de coleta de dados tem sido o mais utilizado na pesquisa sobre ética nos negócios - em 174 pesquisas conduzidas entre 1996 e 2005, 95 (55\%) utilizaram cenários como abordagem metodológica (O’FALLON e BUTTERFIELD, 2005). O Quadro 1 descreve cada um desses cenários.

\section{Quadro 1 - Cenários negociais}

\section{Você é gerente de produto e está negociando um importante contrato para a sua}

Cenário 1 empresa. O resultado dessa negociação determinará sua promoção para gerente regional, além de aumentar significativamente o seu salário. 
Você estará participando de uma negociação com um futuro cliente da sua empresa.

Cenário 2 Antes da negociação, toma conhecimento de que o seu interlocutor tem a reputação de desonesto.

A empresa Alfa é uma fornecedora estável da sua empresa, com a qual mantém uma

Cenário 3 relação de longo prazo, consolidada durante os últimos anos. Você é o responsável pela negociação de um contrato de suprimento de matérias-primas para um novo produto.

Você está negociando um projeto com a empresa Beta. No entanto, em negociações

Cenário 4 anteriores, a empresa Beta demonstrou uma elevada intransigência e inflexibilidade, o que inviabilizou um acordo entre as partes.

Você é gerente regional de uma grande empresa e está negociando com o representante Cenário 5 da empresa Gama, uma pequena empresa de transporte. Fontes asseguraram-lhe que para a empresa Gama esse contrato é muito importante, enquanto para sua empresa existem alternativas disponíveis.

Você é o diretor de produção de uma empresa de manufatura. Para conseguir cumprir

Cenário 6 os seus prazos de entrega, tem de negociar a compra de uma quantidade de matériasprimas com um fornecedor com extrema urgência.

O cenário 1 representava uma situação em que a importância dos assuntos a negociar era elevada. Em uma situação dessas, as pessoas podem sentir-se tentadas a proteger os seus interesses por meio de uma barganha dura ou mesmo sacrificando os seus princípios morais para alcançar os seus objetivos (ROTH \& MURNIGHAN, 1982; VOLKEMA \& FLEURY, 2002). O cenário 2 ilustrava a situação de uma negociação com alguém com a reputação de desonesto. As evidências sugerem que as características do oponente, como a sua reputação ou habilidade negocial, também podem levar um negociador a comportamentos eticamente questionáveis que protejam os seus interesses (BARRY \& BATEMAN, 1996; VOLKEMA, 1997). Tais comportamentos podem ser justificados com base na teoria da equidade (GLASS \& WOOD, 1996). Por sua vez, o cenário 3 apresentava uma negociação em um contexto de relações estáveis entre as partes. Nesses casos, os negociadores reconhecem o risco potencial da utilização de táticas eticamente ambíguas e tendem a revelar uma menor intenção na sua utilização (LEWICKI \& SPENCER, 1991), uma vez que o risco de retaliação ou o potencial embaraço pelo comportamento são elevados (CLARK e outros, 1986). Da mesma forma, as experiências 
passadas entre as partes também influenciam o seu comportamento - situação retratada no cenário 4 . Schweitzer e outros (2004) concluem que o simples impacto de uma negociação falha no passado aumenta a predisposição para a utilização de táticas moralmente questionáveis. Similarmente, Gruder (1971) demonstrou que os negociadores utilizam mais facilmente comportamentos enganosos e fazem menos concessões quando negociam com alguém que anteriormente tentou enganá-los ou que foi demasiado competitivo. O cenário 5, por sua vez, ilustrava uma situação em que existia um desequilíbrio na relação de poder entre as partes. Diversas pesquisas têm permitido concluir que os negociadores, ao avaliarem o seu poder na negociação, decidem se devem competir, colaborar, acomodar ou retirar-se (COSIER \& RUBLE, 1981; PUTNAM \& WILSON, 1982). De um modo geral, os negociadores com mais poder apresentam uma maior predisposição para a utilização de táticas eticamente questionáveis (CROTT e outros, 1980). Por último, a pressão do tempo (cenário 6) também pode justificar a utilização de comportamentos mais competitivos ou moralmente duvidosos, novamente como uma forma de restabelecimento da equidade entre as partes (VOLKEMA \& FLEURY, 2002).

\section{Análise dos dados}

De acordo com a formulação proposta para o modelo de pesquisa, o método de equações estruturais é o tratamento mais adequado para os dados, uma vez que permite avaliar os efeitos das relações diretas e indiretas entre os construtos exógenos e os construtos endógenos do modelo. Dessa forma, vários modelos foram estimados para identificar e testar as relações propostas para cada um dos seis cenários considerados.

\section{RESULTADOS}

Para avaliar em que medida o julgamento moral se encontra correlacionado com a intenção comportamental, começou-se por realizar a análise canônica entre as variáveis que constituem cada um desses construtos. Como a intenção comportamental foi medida em seis cenários que especificavam diferentes condições negociais, foram realizadas seis análises canônicas independentes. Em todas as análises, os resultados indicam que existe uma correlação estatisticamente significativa entre os 
conjuntos de variáveis analisados (teste de Wilks com $\mathrm{p}<0.0001$ para todas as análises), o que parece confirmar que o julgamento moral e a intenção comportamental estão associados.

No entanto, é importante analisar não apenas a correlação direta entre julgamento moral e intenção, mas também como as circunstâncias específicas de uma negociação podem condicionar essa relação. Assim, comparando o julgamento moral com a intenção comportamental em cada cenário específico, poder-se-á concluir em que situações as pessoas agem de acordo com o seu julgamento e em que situações a sua intenção comportamental se desvia significativamente deste. A Tabela 1 apresenta os resultados dos testes $t$, que comparam, para cada cenário com condições específicas, o julgamento moral de cada uma das práticas eticamente questionáveis com a intenção declarada de utilizar esse comportamento nas condições especificadas.

Tabela 1 - Comparação de médias de julgamento e intenção

\begin{tabular}{|c|c|c|c|c|c|}
\hline & & Comportame & ntos eticam & ente ambíguos & \\
\hline & $\begin{array}{c}\text { 1. Coleta } \\
\text { fraudulenta de } \\
\text { informação }\end{array}$ & $\begin{array}{l}\text { 2. Distorção de } \\
\text { informação } \\
\text { material relevante }\end{array}$ & $\begin{array}{l}\text { 3. Ameaças de } \\
\text { abandono da } \\
\text { negociação }\end{array}$ & $\begin{array}{l}\text { 4. Enfraquecimento } \\
\text { da rede de alianças } \\
\text { do outro }\end{array}$ & $\begin{array}{c}\text { 5. Dissimulação } \\
\text { dos interesses e } \\
\text { necessidades }\end{array}$ \\
\hline Julgamento Moral & 4,05 & 2,03 & 2,94 & 2,31 & 4,87 \\
\hline $\begin{array}{l}\text { Cenário } 1 \text { - Negociação } \\
\text { muito importante }\end{array}$ & $4,41 * *$ & $2,40 * *$ & $3,12^{*}$ & 2,37 & 4,92 \\
\hline $\begin{array}{l}\text { Cenário } 2 \text { - Reputação } \\
\text { desonesto da outra parte }\end{array}$ & $4,88 * *$ & $2,62 * *$ & $3,51 * *$ & $3,16^{* *}$ & 4,90 \\
\hline $\begin{array}{l}\text { Cenário } 3 \text { - Relação } \\
\text { estável e de longo prazo }\end{array}$ & 4,09 & 2,05 & 2,89 & 2,27 & $4,16^{* *}$ \\
\hline $\begin{array}{l}\text { Cenário } 4 \text { - Experiências } \\
\text { passadas negativas }\end{array}$ & $4,77 * *$ & $2,44 * *$ & $3,60 * *$ & $2,82 * *$ & 5,05 \\
\hline $\begin{array}{l}\text { Cenário } 5 \text { - Elevado } \\
\text { poder negocial }\end{array}$ & 4,19 & 2,10 & $3,35^{* *}$ & 2,34 & $4,59 *$ \\
\hline $\begin{array}{l}\text { Cenário } 6 \text { - Pressão do } \\
\text { tempo }\end{array}$ & $4,66 * *$ & $2,55 * *$ & 2,97 & 2,44 & $4,27 * *$ \\
\hline
\end{tabular}

Os resultados da Tabela 1 mostram que, quando as condições negociais são desfavoráveis ou desafiadoras, os respondentes declaram uma intenção de utilizar determinadas táticas eticamente questionáveis significativamente maior do que o julgamento que fazem da sua aceitabilidade moral. Os 
resultados permitem concluir que, quando se sentem ameaçadas ou pressionadas, as pessoas se sentem tentadas a agir de uma forma que se desvia negativamente do que julgam moralmente mais apropriado. Por outras palavras, os negociadores ficam mais propensos a utilizar táticas eticamente ambíguas. Os cenários que revelaram uma influência mais significativa na intenção comportamental em relação ao julgamento foram tanto a perspectiva de negociar com alguém com uma reputação desonesta (cenário2) como com alguém que se mostrou intransigente e inflexível em situações passadas (cenário 4), o que sugere que, nessas condições específicas, os respondentes se sentem mais legitimados a adotar algumas formas de engano, mesmo que isso implique um desvio considerável relativamente ao seu julgamento moral. Também a pressão do tempo (cenário 6) e a importância da negociação (cenário 1) parecem influenciar um comportamento menos ético.

Por outro lado, quando as condições negociais são favoráveis, os negociadores tendem a adotar um comportamento mais consistente com o seu julgamento moral, evitando mesmo algumas formas de engano mais sutis e mais aceitáveis, como a dissimulação. De fato, os resultados mostram que, no caso de negociações que ocorrem no contexto de continuidade de relações (cenário 3) ou nas quais a pessoa detém mais poder negocial (cenário 5), o comportamento se mantém mais consistente com o julgamento, e os desvios que ocorrem são positivos e têm como objetivo evitar riscos desnecessários. A exceção é uma maior propensão para estratégias de força, como as ameaças e o blefe, quando um negociador sente um desequilíbrio de poder favorável na relação entre as partes (cenário 5).

Para testar em que medida alguns traços de personalidade, especificamente a confiança interpessoal e a competitividade, ajudam a explicar esses desvios entre julgamento e intenção, foram então estimados vários modelos estruturais de forma a testar as relações entre os construtos propostos para cada cenário. O objetivo consiste em compreender, para cada situação específica, como o julgamento e as características individuais do respondente condicionam a intenção comportamental. Os modelos estruturais estimados utilizaram os traços de personalidade como construtos exógenos e o julgamento moral e a intenção comportamental como construtos endógenos. Os construtos exógenos foram operacionalizados pelas quatro variáveis que medem a confiança, e as quatro que medem a competitividade dos respondentes, e os construtos endógenos foram operacionalizados pelas médias das cinco variáveis que medem o julgamento moral e a intenção comportamental. Para cada cenário foram estimados os modelos que integram relações diretas e indiretas entre os construtos, optando-se por aqueles que revelaram o melhor ajustamento dos dados, considerando para o efeito as diferenças de 
$\chi^{2}$ e alguns índices de ajustamento dos modelos. A Tabela 1 apresenta os indicadores dos modelos estruturais para cada cenário.

Tabela 2 - Indicadores dos modelos estruturais

\begin{tabular}{lcccccc}
\hline & $\chi^{\mathbf{2}}$ & gl & $\chi^{\mathbf{2} / g l}$ & AGFI & GFI & RMSEA \\
\hline Modelo Cenário 1 & 114,4 & 32 & 3,58 & 0,94 & 0,98 & 0,057 \\
Modelo Cenário 2 & 107,9 & 31 & 3,48 & 0,92 & 0,97 & 0,069 \\
Modelo Cenário 3 & 117,3 & 32 & 3,67 & 0,94 & 0,98 & 0,054 \\
Modelo Cenário 4 & 108,0 & 32 & 3,38 & 0,92 & 0,97 & 0,068 \\
Modelo Cenário 5 & 104,5 & 31 & 3,37 & 0,92 & 0,97 & 0,067 \\
Modelo Cenário 6 & 106,1 & 32 & 3,32 & 0,93 & 0,98 & 0,060 \\
\hline
\end{tabular}

Após a identificação dos modelos que melhor se ajustavam aos dados, foram analisadas as estimativas dos parâmetros do modelo em cada cenário de forma a avaliar as hipóteses de pesquisa propostas. Esses parâmetros são apresentados na Tabela 2.

Tabela 3 - Parâmetros dos modelos estruturais

\begin{tabular}{c|cccccc}
\hline & Cenário 1 & Cenário 2 & Cenário 3 & Cenário 4 & Cenário 5 & Cenário 6 \\
\hline$\gamma_{1,1}$ & $0,24 * *$ & $0,24 * *$ & $0,24 * *$ & $0,24 * *$ & $0,24 * *$ & $0,24 * *$ \\
$\gamma_{2,1}$ & -- & $0,05 \mathrm{~ns}$ & -- & -- & $0,07 \mathrm{~ns}$ & -- \\
$\gamma_{1,2}$ & $-0,16 *$ & $-0,16 *$ & $-0,16 *$ & $-0,16 *$ & $-0,16 *$ & $-0,16 *$ \\
$\gamma_{2,2}$ & $-0,07 \mathrm{~ns}$ & $-0,18 * *$ & $-0,16 *$ & $-0,18 * *$ & $-0,07 \mathrm{~ns}$ & $-0,19 * *$ \\
$\beta_{2,1}$ & $0,67 * *$ & $0,62 * *$ & $0,40 * *$ & $0,60 * *$ & $0,57 * *$ & $0,51 * *$ \\
\hline$* * p<0,01 ; * p<0,05 ; n s=$ não significante.
\end{tabular}

Os resultados permitem concluir que, tal como defende a $\mathbf{H}_{\mathbf{1}}$, a intenção comportamental é fortemente influenciada pelo julgamento moral em todos os cenários avaliados $\left(0,40<\beta_{2,1}<0,67\right.$, todos com $\mathrm{p}<0,01)$. De fato, a relação entre atitudes e intenções sugerida pelas teorias da ação racional e do comportamento planejado parecem encontrar suporte empírico nos resultados desta pesquisa. Os resultados dos modelos estruturais são também consistentes no que se refere à influência das dimensões de personalidade estudadas no julgamento moral de práticas negociais eticamente duvidosas. Em todos os cenários, se identifica uma relação positiva entre a competitividade e o julgamento moral $\left(\gamma_{1,1}=\right.$ $0,24, \mathrm{p}<0,01)$, o que permite concluir que as pessoas mais competitivas avaliam os dilemas éticos na 
negociação com mais tolerância, corroborando assim a $\mathbf{H}_{2 \mathbf{a}}$. Por outro lado, também se identificaram relações estatisticamente significativas entre a confiança interpessoal e o julgamento moral para todos os cenários $\left(\gamma_{1,2}=-0,16, p<0,05\right)$, o que significa que as pessoas com maior predisposição à confiança julgam a moralidade das práticas eticamente ambíguas com mais rigor e intolerância. Este resultado permite suportar a $\mathbf{H}_{3 \mathbf{a}}$.

No entanto, enquanto os modelos relativos aos cenários 1 (objeto da negociação é muito importante) e 5 (poder negocial relativo elevado) não identificam nenhuma relação significativa entre os construtos exógenos e a intenção comportamental (Figura 2), os restantes modelos que avaliam outras condições negociais identificam uma relação direta, estatisticamente significativa, entre a confiança interpessoal e a intenção comportamental $(-0,16<\gamma 2,2<-0,19, \mathrm{p}<0,05)$. Dessa forma, os resultados sugerem que a confiança interpessoal não só influencia a intenção comportamental indiretamente, via julgamento moral, mas também exerce uma influência direta na intenção de agir em situações negociais específicas (Figura 3). O coeficiente negativo dessa relação indica que, quanto maior for a confiança interpessoal dos respondentes, menor será a intenção de utilizar táticas eticamente ambíguas, independentemente do seu julgamento moral dessas táticas. Esse resultado é elucidativo quanto ao papel da confiança interpessoal no processo de tomada de decisão ética, sugerindo que esta não só influencia a forma como as pessoas julgam a moralidade, mas também influencia a forma como se comportam. Esse resultado permite corroborar a $\mathbf{H}_{3 \mathbf{b}}$. Por outro lado, não se identificaram relações diretas entre a competitividade e a intenção comportamental em nenhum dos cenários testados, pelo que a $\mathbf{H}_{2 \mathbf{b}}$ não encontra suporte empírico. Contudo, existe uma influência indireta dessa variável na intenção comportamental, via julgamento moral.

\section{Figura 2 - Modelo estrutural - Cenário 1 (Negociação de elevada importância)}

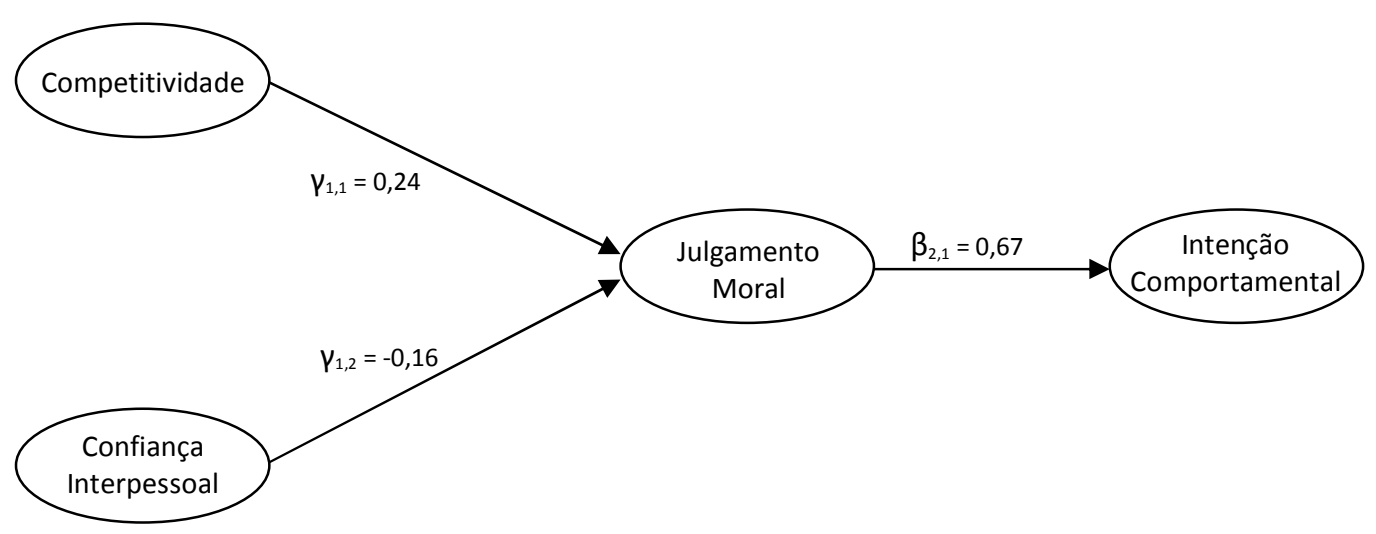


Figura 3 - Modelo estrutural - Cenário 2 (Oponente com reputação de desonesto)

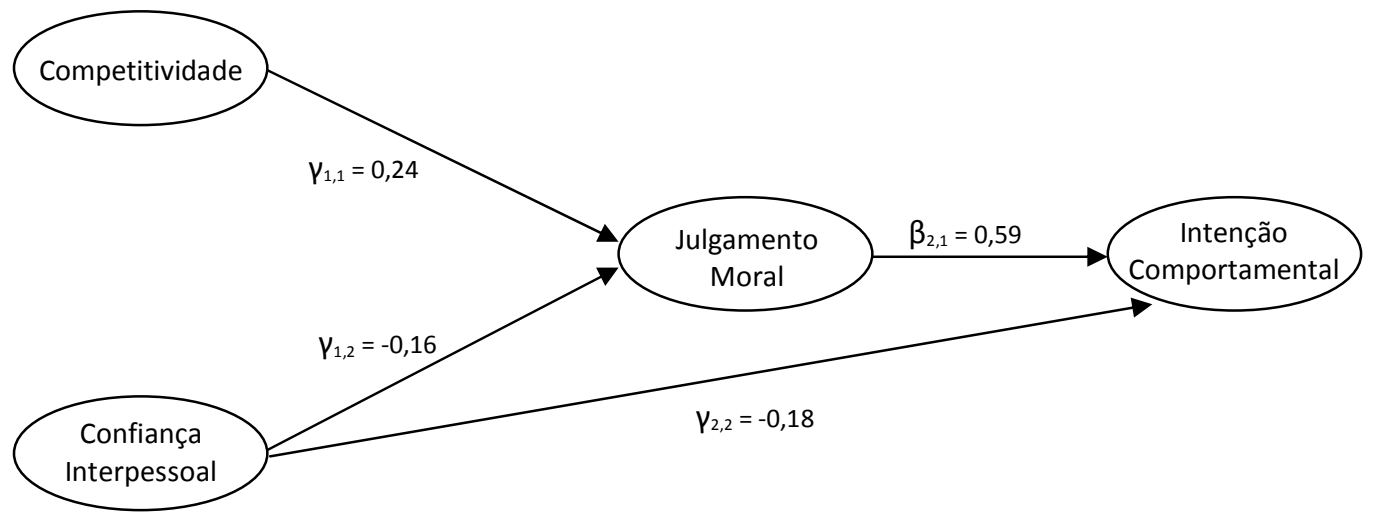

\section{DISCUSSÃO}

Os resultados desta pesquisa permitem corroborar a relação entre julgamento moral e intenção comportamental, como postulado pelas teorias da ação racional (FISHBEIN e AJZEN, 1975) e do comportamento planejado (AJZEN, 1985; 1991). De fato, mesmo em situações que envolvem dilemas éticos, pode concluir-se que a intenção comportamental perante práticas eticamente questionáveis é determinada, em grande medida, pelo julgamento moral que um indivíduo faz dessas práticas. No entanto, outros fatores também podem condicionar a intenção comportamental das pessoas, entre os quais se destacam as circunstâncias específicas da situação. Ou seja, ao decidir como se comportar, uma pessoa é influenciada não apenas pelo seu julgamento moral, mas também por variáveis situacionais e potenciais consequências da sua ação. Isso significa que, ao analisar a situação específica, uma pessoa poderá adotar um comportamento que se desvie substancialmente do seu julgamento moral.

Os resultados sugerem que, quando as condições negociais são desfavoráveis ou desafiadoras, os gestores ficam mais propensos a utilizar táticas negociais eticamente ambíguas, o que pode ser interpretado como uma tentativa de restabelecer a justiça e corrigir uma eventual iniquidade na relação entre as partes (GLASS e WOOD, 1996), ou como um mecanismo que permite as comunicações necessárias a uma negociação sem expor demasiadamente um negociador (STRUDLER, 1995). 
Outras pesquisas que exploram o impacto dessas influências situacionais corroboram os resultados encontrados. Por exemplo, alguns estudos concluem que, por vezes, os negociadores sacrificam os seus princípios morais quando os assuntos em discussão são demasiado importantes para eles próprio ou para a sua organização (ROTH e MURNIGHAN, 1982; VOLKEMA e FLEURY, 2002), enquanto outros sugerem que os negociadores são menos verdadeiros na sua comunicação e mais seletivos na sua troca de informação quando se encontram pressionados para alcançar um acordo (YUKL e outros, 1976). Smith e outros (1982) sugerem que isso acontece porque a pressão do tempo aumenta a percepção do negociador relativamente à inflexibilidade da outra parte, enquanto Baron (1988) argumenta que a pressão do tempo diminui a percepção do negociador relativamente à honestidade da contraparte.

Por outro lado, quando as condições negociais são favoráveis, os negociadores tendem a adotar um comportamento mais consistente com o seu julgamento moral, revelando mesmo uma menor intenção em utilizar táticas negociais eticamente questionáveis. Por exemplo, quando as negociações se inserem no quadro de relações estáveis, os negociadores reconhecem o potencial risco da utilização de táticas eticamente ambíguas, revelando menor intenção na sua utilização (LEWICKI e SPENCER, 1991), algo que é corroborado por esta pesquisa. Já no caso de negociações esporádicas e de curto prazo, as partes tendem a assumir comportamentos mais conflituosos e eticamente questionáveis, uma vez que o risco de retaliação ou o potencial embaraço pelo comportamento é reduzido (CLARK e outros, 1986). Numa situação de maior poder negocial, os negociadores também sentem uma menor necessidade de utilizar táticas eticamente ambíguas. Por outro lado, sentem-se mais legitimados para utilizar estratégias de pressão, como as ameaças e o blefe (CROTT e outros, 1980), algo que também é corroborado por esta pesquisa.

Esta pesquisa permitiu ainda analisar a influência de diferenças individuais no processo de tomada de decisão ética de uma forma integrada. Os resultados sugerem que os respondentes com uma maior confiança interpessoal, ou seja, mais predispostos a confiar nos outros, são aqueles que julgam as práticas negociais eticamente questionáveis como mais reprováveis, ou seja, tendem a adotar padrões morais mais rigorosos no seu julgamento moral. Rotter (1980) explica que isso acontece porque os indivíduos com uma elevada confiança interpessoal acreditam que os outros vão se comportar de uma forma honesta e confiável e não irão usar de forma oportunista a informação que compartilham durante o processo negocial. 
Por outro lado, os resultados confirmam ainda que as pessoas mais competitivas julgam as práticas negociais eticamente ambíguas com uma maior tolerância, ou seja, reconhecem uma maior legitimidade moral a essas práticas. Os resultados parecem sugerir que os negociadores mais competitivos veem a negociação como um jogo com regras próprias cujo objetivo consiste em maximizar os resultados próprios, tal como defendido por Carr (1968). Para esse autor, esconder informação, fazer blefe, encobrir ou exagerar dados e fatos pertinentes são comportamentos normais e legítimos no mundo de negócios. Para ele, os executivos que não o fazem ignoram as oportunidades permitidas pelas "regras do jogo" e, consequentemente, ficam em desvantagem nas suas relações empresariais e negociais. De fato, alguns autores defendem que negociação honesta não é, por definição, negociação, uma vez que o engano e a mentira são inerentes ao processo de troca (PEPPET, 2002; WHITE, 1980). Para esses autores, negociar significa tomar partido, defender interesses, assumir uma postura competitiva, pelo que algumas práticas de engano e mentira em negociação são não só aceites como, por vezes, apreciadas no contexto das negociações empresariais e legais (PEPPETT, 2002).

No entanto, a influência desses traços de personalidade no processo de tomada de decisão ético não se dá apenas via julgamento moral. De fato, foram identificadas relações diretas significativas entre a confiança interpessoal e a intenção comportamental em quatro dos seis cenários avaliados. Especificamente, pessoas mais desconfiadas tendem a revelar uma maior predisposição para utilizar táticas eticamente ambíguas, não só porque as julgam moralmente mais aceitáveis, como também porque avaliam esse comportamento como o mais adequado em determinadas situações. Por exemplo, os resultados sugerem que pessoas mais desconfiadas, ao negociar com alguém que tem uma reputação de desonesto (cenário 2) ou que no passado se demonstrou demasiado competitivo ou intransigente (cenário 4), antecipam que estes vão utilizar comportamentos enganosos, pelo que se mostram mais propensas a utilizar práticas negociais que envolvam formas de engano ou de inverdade, de forma a restabelecer a justiça e corrigir uma eventual iniquidade na relação entre as partes, tal como sustenta a teoria da equidade (GLASS e WOOD, 1996). Por outro lado, num contexto relacional estável entre as partes (cenário 3), as pessoas mais desconfiadas revelam uma maior intenção de utilizar táticas eticamente questionáveis. Esse resultado corrobora os argumentos de Cramton e Dees (1993) ao defenderem a tese de que ambientes negociais carentes de confiança incentivam o comportamento oportuno e amoral das partes. Para esses autores, a existência de uma relação de confiança entre as partes é a condição necessária para o comportamento ético na negociação. Esses resultados permitem 
concluir que a confiança tem uma relação dinâmica com o processo de tomada de decisão ética, condicionando não só o julgamento moral dos envolvidos, como também o comportamento em determinadas situações.

\section{CONCLUSÃO}

$\mathrm{Na}$ pesquisa sobre a ética na tomada de decisão em administração, o julgamento moral é frequentemente utilizado como proxy do comportamento, teorizando que esse julgamento moral determina a intenção de adotar um determinado comportamento eticamente questionável (REST, 1986). No entanto, outros fatores, que não o julgamento moral, podem influenciar a intenção comportamental e, consequentemente, o comportamento efetivo. Os resultados da presente pesquisa permitem explorar a complexidade das influências situacionais e individuais nessa relação. Conclui-se que o processo de tomada de ética dos gestores é condicionado não só pela racionalidade instrumental dos atores, mas também por diferenças individuais e pelas condições concretas de negociação, como é de se esperar de qualquer indivíduo sujeito a pressões ambientais. A ambiguidade ética inerente a qualquer processo de negociação é um fenômeno natural que decorre da individualidade dos envolvidos, assim como das situações nas quais eles diariamente se enfrentam.

Os resultados desta pesquisa permitem corroborar a relação entre julgamento moral e intenção comportamental, no entanto sugerem que existem desvios significativos nessa relação. Ao comparar a intenção de agir em seis cenários negociais com o julgamento prévio que o respondente fazia de determinados comportamentos, conclui-se que as condições específicas de cada situação exercem uma influência significativa no processo de tomada de decisão ética, fazendo com que a intenção comportamental se desvie significativamente do julgamento moral, de forma a adaptar-se às condições negociais específicas enfrentadas. Conclui-se também que as diferenças individuais na personalidade também exercem uma influência significativa no processo de tomada de decisão ética. De fato, a competitividade está associada a um julgamento moral mais tolerante, enquanto a confiança interpessoal está relacionada com um julgamento moral mais rigoroso.

Além disso, os resultados sugerem que a relação de confiança também influencia diretamente a intenção comportamental dos negociadores, fazendo com que, em algumas situações, o seu comportamento se desvie do julgamento moral. Os resultados dessa pesquisa sugerem uma relação 
dinâmica dos negociadores com a situação. De fato, a análise dos resultados revela que, quando a reputação da outra parte for negativa, as relações forem interpretadas como instáveis ou as experiências passadas forem consideradas frustrantes, os respondentes revelam maior intenção para usar comportamentos moralmente questionáveis. Os sujeitos de pesquisa revelam aqui sua imersão social, as consequências da relação interpessoal na eticidade de tomada de decisão. A qualidade dessa relação se reflete em comportamentos mais éticos na negociação. Indiretamente, essa reflexão corrobora os argumentos defendidos pelo princípio de confiança mútua de Cramton e Dees (1991), os quais advogam investir na qualidade e na confiança dessa relação para obter decisões mais éticas nas negociações reais.

Esses resultados apontam para a necessidade de empreender novos rumos de pesquisa que explorem essa natureza dinâmica da relação entre a situação e a tomada de decisão por parte do negociador. Além das relações interpessoais, outras dimensões podem modificar-se em situações concretas negociais ou até mesmo no próprio negociador. Teorias recentes têm revelado o potencial do conceito de sensemaking, que se refere à ideia de que os indivíduos são continuamente bombardeados por informações situacionais e organizacionais ambíguas que, de alguma forma, são percebidas, interpretadas e readaptadas como base de ação futura (WEICK, 1995). A relação indivíduo - situação é uma relação de natureza dinâmica, na qual os dois lados são sujeitos a transformações. No entanto, esforços teóricos nessa direção ainda são escassos.

\section{REFERÊNCIAS}

ALEXANDER, C. S; BECKER, H. J. The use of vignettes in survey research. Public Opinion Quarterly, v. 42, n. 1, p. 93-104, 1978.

AJZEN, I. From intentions to actions: a theory of planned behavior. In: KUHL, J.; BECKMANN, J. (Eds). Action control: from Cognition to Behavior (p. 11-39). Heidelberg, Germany: Springer, 1985.

AJZEN, I. The Theory of Planned Behavior. Organizational Behavior \& Human Decision Processes, v. 50, n. 2, p. 179-211, 1991. 
BARRY, B; ROBINSON, R. Ethics in conflict resolution: The ties that bind. International Negotiation, v. 7, n. 2, p. 137-142, 2002.

BASS, K; BARNETT, T; BROWN, G. Individual difference variables, ethical judgments, and behavioral intentions. Business Ethics Quarterly, v. 9, n. 2, p. 183-206, 1999.

BROWN, T. A; SAUTTER, J. A; LitTVAY, L; SAUTTER, A. C; BEARNES, B. Ethics and personality: empathy and narcissism as moderators of ethical decision making in business students. Journal of Education for Business, v. 85, n. 4, p. 203-208, 2010.

BUTLER, J. K. Trust expectations, information sharing, climate of trust, and negotiation effectiveness and efficiency. Group and Organization Management, v. 24, n. 2, p. 217-238, 1999.

CAllanAn, G. A; ROTENBERRY, P. F; PERRI, D. F; OEHLERS, P. Contextual factors as moderators of the effect of employee ethical ideology on ethical decision-making. International Journal of Management, v. 27, n. 1, p. 52-75, 2010.

CRAVER, C. Negotiation styles: the impact on bargaining transactions. Dispute Resolution Journal, v. 58, n. 1, p. 49-56, 2003.

DE CREMER, D; VAN DIJK, E; PILLUTLA, M. Explaining unfair offers in ultimatum games and their effects on trust: An experimental approach. Business Ethics Quarterly, v. 20, n. 1, p. 107-126, 2010 .

DEES, J; CRAMTON, P. Shrewd bargaining on the moral frontier: toward a theory of morality in practice. Business Ethics Quarterly, v. 1, n. 2, p. 135-167, 1991.

DEES, J; CRAMTON, P. Deception and mutual trust: a reply to Strudler. Business Ethics Quarterly, v. 5, n. 4, p. 823-832, 1995. 
EAGLY, A; CHAIKEN, S. The Psychology of Attitudes. Forth Worth, TX: Harcourt Brace Jovanovich College Publishers, 1993.

ELAHEE, M; BROOKS, C. Trust and negotiation tactics: perceptions about business-to-business negotiations in Mexico. The Journal of Business \& Industrial Marketing, v. 19, n. 6, p. 397-404, 2004.

FEIDAKIS, A; TSAOUSSIS, A. Competitiveness, gender and ethics in legal negotiations: some empirical evidence. International Negotiation: A Journal of Theory and Practice, v. 14, n. 3, p. 537$570,2009$.

FRITZSCHE, D. J. A model of decision-making incorporating ethical values. Journal of Business Ethics, v. 10, n. 11, 841-852, 1991.

GLASS, R; WOOD W. Situational determinants of software piracy: an equity theory perspective. Journal of Business Ethics, v. 15, n. 11, p. 1189-1198, 1996.

GOOLBSY, J. R; HUNT, S. D. Cognitive moral development and marketing. Journal of Marketing, v. 56, n. 1, p. 55-68, 1992.

GRANOVETTER, M. Economic action and social structure: the problem of embeddedness. American Journal of Sociology, v. 91, n. 3, p. 481-510, 1985.

HOSMER, L. T. Trust: the connecting link between organizational theory and philosophical ethics. Academy of Management Review, v. 20, n. 2, p. 379-403, 1995.

HUNT, S; VITELL, S. A general theory of marketing ethics. Journal of Macromarketing, v. 8, n. 2, p. 5-16, 1986.

JONES, T. M. Ethical decision making by individuals in organizations: An issue-contingent model. Academy of Management Review, v. 16, n. 2, p. 366-395, 1991. 
KIM, M; HUNTER, J. E. Relationships among attitudes, behavioral intentions, and behavior: a metaanalysis of past research, part 2. Communication Research, v. 20, n.3, p. 331-364, 1993.

LEWICKI, R; ROBINSON, R. Ethical and unethical bargaining tactics: an empirical study. Journal of Business Ethics, v. 17, n. 6, p. 665-682, 1998.

LEWICKI, R. J; SAUNDERS, D. M; BARRY, B. Negotiation. 6. ed. Boston: McGraw-Hill, 2009.

LEWICKI, R. J; TOMLINSON, E. C; GILLESPIE, N. Models of interpersonal trust development: theoretical approaches, empirical evidence and future directions. Journal of Management, v. 32, n 6, p. 991-1022, 2006.

MENKEL-MEADOW, C; WHEELER, M. (Eds). What's Fair: Ethics for Negotiators. San Francisco: Jossey-Bass, 2004.

MINTU-WIMSATT, A. Personality and negotiation style: the moderating effects of cultural context. Thunderbird International Business Review, v. 44, n. 6, p. 729-748, 2002.

MURNIGHAN, K; BABCOCK, L; THOMPSON, L; PITTUTLA, M. The information dilemma in negotiations: effects of experience, incentives, and integrative potential. International Journal of Conflict Management, v. 10, n. 4, p. 313-339, 1999.

O'FALLON, M; BUTTERFIELD, K. A review of the empirical ethical decision-making literature: 1996-2003. Journal of Business Ethics, v. 59, n. 4, p. 375-413, 2005.

OLEKALNS, M; SMITH, P. L. Mutually dependent: power, trust, affect and the use of deception in negotiation. Journal of Business Ethics, v. 85, n. 3, p. 347-365, 2009.

PEPPET, S. R. Can saints negotiate? A brief introduction to the problems of perfect ethics in bargaining. Harvard Negotiation Law Review, v. 7, n.1, p. 83-96, 2002. 
PROVIS, C. Honesty in negotiation. Business Ethics: A European Review, v. 9, n. 1, p. 3-12, 2000.

ROBINSON, R; LEWICKI, R. J; DONAHUE, E. M. Extending and testing a five factor model of ethical and unethical bargaining tactics: introducing the SINS scale. Journal of Organizational Behavior, v. 21, n. 6, p. 649-664, 2000.

REST, J. R. Moral Development: Advances in Research and Theory. New York: Praeger, 1986.

RIVERS, C; LYTLE, A. L. Lying, cheating Foreigners! Negotiation ethics across cultures. International Negotiation, v. 12, n. 1, p. 1-28, 2007.

ROUSSEAU, M; SITKIN, S; BURT, R; CAMERER, C. Not so different at all: a cross-discipline view of trust. Academy of Management Review, v. 23, n. 3, p. 393-404, 1998.

ROTH, A; MURNIGHAN, K. The role of information in bargaining: an experimental study. Econometrica, v. 50, n. 5, p. 1123-1142, 1982.

ROTTER, J. B. Interpersonal trust, trustworthiness, and gullibility. American Psychologist, v. 35, n. 1, p. 1-7, 1980.

RYCKMAN, R. M; HAMMER, M; KACZOR, L; GOLD, J. Construction of a personal development competitive attitude scale. Journal of Personality Assessment, v. 66, n. 2, p. 374-385, 1996.

SANKARAN, S; BUI, T. Ethical attitudes among accounting majors: an empirical study. Journal of American Academy of Business, v. 3, n. 1/2, p. 71-76, 2003.

SPARKS, J. R; PAN, Y. Ethical judgments in business ethics research: definition, and research agenda. Journal of Business Ethics, v. 91, n. 3, p. 405-418, 2010.

STRUDLER, A. On the ethics of deception in negotiation. Business Ethics Quarterly, v. 5, n. 4, p. 805$822,1995$. 
TREVINO, L. K. Ethical decision making in organizations: a person-situation interactionist model. Academy of Management Review, v. 11, n. 3, p. 601-617, 1986.

TREVINO, L. K; WEAVER, G. R; REYNOLDS, S. J. Behavioral ethics in organizations: a review. Journal of Management, v. 32, n. 6, p. 951-990, 2006.

UZZI, B. Social structure and competition in interfirm networks: the paradox of embeddedness. Administrative Science Quarterly, v. 42, n. 2, p. 35-67, 1997.

VOLKEMA, R. J; FLEURY, M. T. L. Alternative negotiation conditions and the choice of negotiation tactics: a cross-cultural comparison. Journal of Business Ethics, v. 36, n. 4, p. 381-398, 2002.

VOLKEMA, R. J; FLECK, D; HOFMEISTER-TOTH, A. Ethicality in negotiation: an analysis of attitudes, intentions and outcomes. International Negotiation, v. 9, n. 2, p. 315-339, 2004.

WEBER, J. Scenarios in business ethics research: review, critical assessment, and recommendations. Business Ethics Quarterly, v. 2, n. 2, p. 137-159, 1992.

WHITE, J. J. Machiavelli and the bar: ethical limitations on lying in negotiation. American Bar Foundation Research Journal, v. 5, n. 4, 926-938, 1980. 